\title{
The influence of thermal annealing on structure and oxidation of iron nanowires
}

\author{
Marcin Krajewski, \\ Katarzyna Brzózka, \\ Bogumił Górka, \\ Wei-Syuan Lin, \\ Hong-Ming Lin, \\ Tadeusz Szumiata, \\ Michał Gawroński, \\ Dariusz Wasik
}

\begin{abstract}
Raman spectroscopy as well as Mössbauer spectroscopy were applied in order to study the phase composition of iron nanowires and its changes, caused by annealing in a neutral atmosphere at several temperatures ranging from $200^{\circ} \mathrm{C}$ to $800^{\circ} \mathrm{C}$. As-prepared nanowires were manufactured via a simple chemical reduction in an external magnetic field. Both experimental techniques proved formation of the surface layer covered by crystalline iron oxides, with phase composition dependent on the annealing temperature $\left(T_{\mathrm{a}}\right)$. At higher $T_{\mathrm{a}}$, hematite was the dominant phase in the nanowires.
\end{abstract}

Key words: amorphous iron and iron oxides • iron nanowires • Mössbauer spectroscopy • Raman spectroscopy - thermal annealing

M. Krajewski, D. Wasik

Institute of Experimental Physics,

Faculty of Physics,

University of Warsaw,

69 Hoża Str., 00-681 Warsaw, Poland

K. Brzózka ${ }^{\bowtie}$, B. Górka, T. Szumiata, M. Gawroński Department of Physics,

Faculty of Mechanical Engineering,

University of Technology and Humanities in Radom,

54 Krasickiego Str., 26-600 Radom, Poland,

Tel.: +48 48361 7846, Fax: +48 483617075 ,

E-mail: k.brzozka@uthrad.pl

W.-S. Lin, H.-M. Lin

Department of Materials Engineering,

Tatung University,

Taipei, 104, Taiwan, R.O.C.

Received: 18 June 2014

Accepted: 2 November 2014

\section{Introduction}

Magnetic nanomaterials based on iron or iron compounds are extensively studied due to applications in many fields such as: medicine, pharmacy (drug delivery systems) [1], data storage [2], catalysis [3], gas adsorbents [4], etc. Apart from chemical composition, their sizes and shapes play also a significant role in the possible applications. It has been already reported that nanomaterials in a form of nanowires usually exhibit superior magnetic properties in comparison with equivalent nanoparticles of similar structure, mass, and volume [5]. Therefore, iron nanowires or their oxide derivatives are supposed to be one of the most interesting magnetic nanomaterials. This work is focused on the structural properties of iron nanowires (Fe NWs) which were annealed at different temperatures in argon atmosphere.

\section{Experimental details}

So far, plenty of preparation methods of iron or iron oxide nanowires have been reported in the literature [6]. However, most of them lead to the incorporation of various impurities inside the nanowire structure that need quite expensive techniques or chemicals. Hence, in this work Fe NWs were manufactured via a simple chemical reduction of aqueous solution of hexahydrated iron (III) chloride $(0.5 \mathrm{M}$ $\mathrm{FeCl}_{3} \cdot 6 \mathrm{H}_{2} \mathrm{O}$; Sigma Aldrich) with a reductive agent of sodium borohydride (1 $\mathrm{M} \mathrm{NaBH}_{4}$; Sigma Aldrich) 


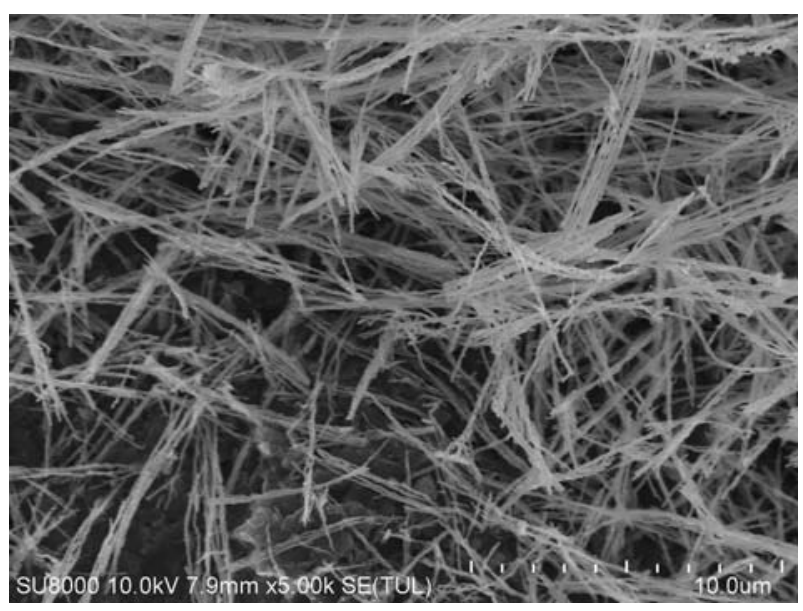

Fig. 1. SEM image of as-prepared iron nanowires with a magnification of 5000 times.

aqueous solution. This reaction was carried out in the external magnetic field $(\sim 0.2 \mathrm{~T})$ and also it was performed in the neutral argon-atmosphere to reduce creation of iron oxides. More details about the growth of as-prepared Fe NWs can be found at the previous publication [6]. Later, such prepared nanowires were annealed at 200,300,400,500, and $800^{\circ} \mathrm{C}$ in a tube furnace under a constant argon flow.

The dimensions of the studied iron nanowires were estimated by means of a field-emission scanning electron microscope (FE-SEM Hitachi SU8020). The average diameter and length of Fe NWs are $90 \mathrm{~nm}$ and $5 \mu \mathrm{m}$, respectively. An exemplary image of the investigated nanomaterial is shown in Fig. 1.

The next step of this work was dedicated to structural studies of as-prepared as well as annealed iron nanowires. The Raman investigations were performed at ambient conditions by applying a T64000 Series II Raman spectrometer equipped with Nd-YAG laser $(\lambda=532 \mathrm{~nm})$ of continuous wave excitation. One of advantages of Raman measure-

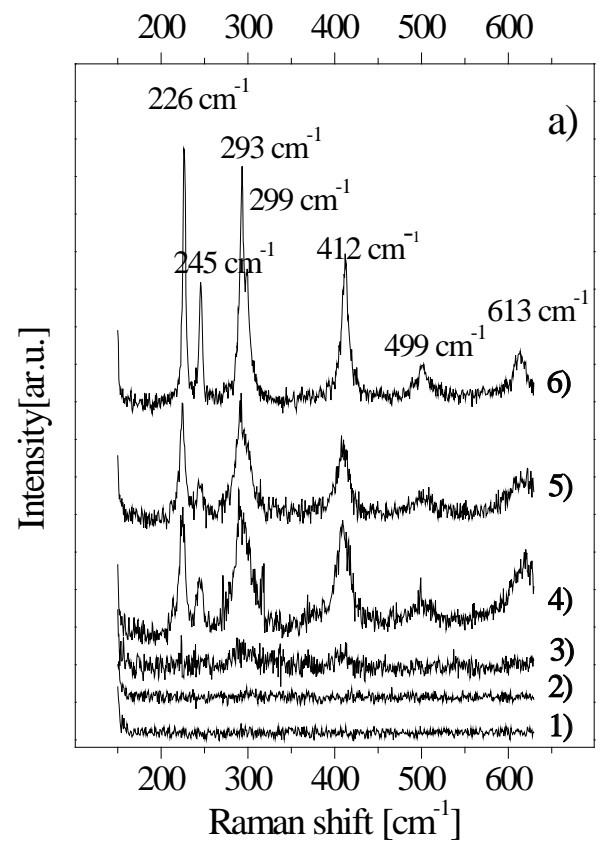

ments is the simplicity of samples preparation. In this work, few milligrams of each studied sample were placed on the glass microscope slide and then it was exposed to the laser irradiation. However, it is known that the laser irradiation can lead to a significant sample heating during the measurement process and it can have an influence on the structure of the studied nanomaterials and also on the final results. This problem was solved by applying the filters which reduced the laser power to $0.03 \mathrm{~mW}$ and allowed to perform the Raman measurements without any negative effects on the studied samples.

Transmission Mössbauer measurements were carried out at room temperature by the use of a standard Mössbauer spectrometer (POLON) and ${ }^{57} \mathrm{Co} / \mathrm{Rh}$ source of $\gamma$-radiation placed on a vibrator, working in a constant acceleration mode. The nanowires were deposited into a holder made of boron nitride. As-prepared sample was also investigated using CEMS (conversion electrons Mössbauer spectroscopy) spectrometer equipped with a one-wire flow electron counter supplied with $\mathrm{He}+0.5 \% \mathrm{CH}_{4}$ gas mixture. The specimen was prepared by deposition of the nanowires on an aluminum foil (in order to achieve good electric contact) using Vaseline. In both cases, a vertical geometry of the gamma beam was used. All the spectra were analyzed by means of NORMOS program that utilized the conventional least square procedure with additional smoothing terms.

\section{Results and discussion}

The Raman spectra obtained for Fe NWs are presented in Fig. 2a and their more detailed extension is shown in Fig. 2b. In general, not all the vibrational modes are active in Raman spectroscopy. This technique allows recording a signal when none extremum (neither maximum nor minimum) of molecule po-

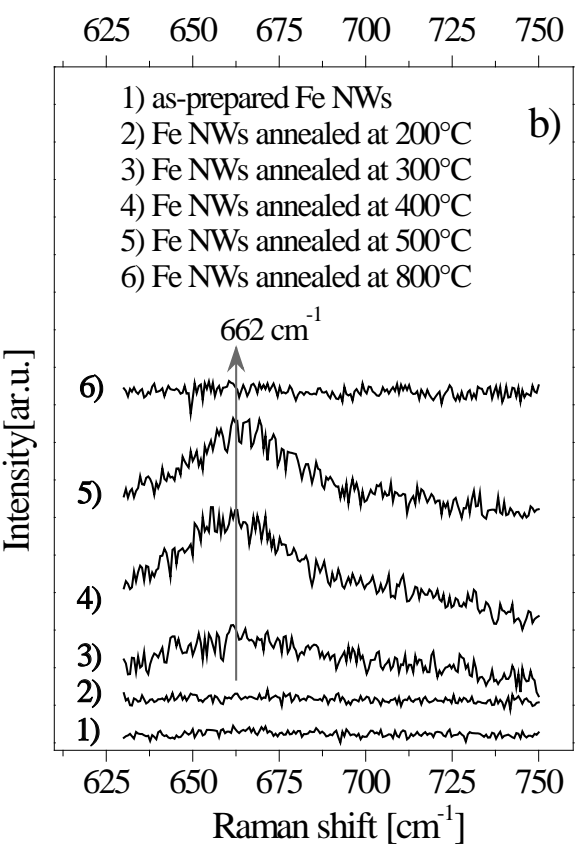

Fig. 2. The Raman spectra of initial as well as annealed (at different temperature $T_{\mathrm{a}}$, under Ar atmosphere) Fe-nanowires (a) and their more detailed extensions (b). 
Table 1. Specification of Raman active vibrational modes and corresponding wavenumbers - characteristic of iron oxides

\begin{tabular}{lc}
\hline \multicolumn{1}{c}{ Type of iron oxide } & Raman active vibrational modes (wavenumbers) \\
\hline $\mathrm{Fe}_{3} \mathrm{O}_{4}$ & $\mathrm{~A}_{1 \mathrm{~g}}\left(662 \mathrm{~cm}^{-1}\right)$ \\
$\alpha-\mathrm{Fe}_{2} \mathrm{O}_{3}$ & $\mathrm{~A}_{1 \mathrm{~g}}\left(226 \mathrm{~cm}^{-1}\right) ; E_{\mathrm{g}}\left(245 \mathrm{~cm}^{-1}\right) ; E_{\mathrm{g}}\left(293 \mathrm{~cm}^{-1}\right) ; E_{\mathrm{g}}\left(299 \mathrm{~cm}^{-1}\right) ; E_{\mathrm{g}}\left(412 \mathrm{~cm}^{-1}\right) ;$ \\
$\mathrm{A}_{1 \mathrm{~g}}\left(499 \mathrm{~cm}^{-1}\right) ; E_{\mathrm{g}}\left(613 \mathrm{~cm}^{-1}\right)$
\end{tabular}

larizability occurs in the equilibrium point during the vibration $\left((\mathrm{d} \alpha / \mathrm{dq})_{\mathrm{e}} \neq 0\right.$, where $\alpha$ - polarizability, $\mathrm{q}$ - normal coordinate, and e - equilibrium point). Therefore, it is a useful experimental technique to study the structures of iron oxides but it does not provide any information about structural properties of iron. In order to analyze the results, the Raman vibrational modes and corresponding positions of iron oxides bands were determined on the basis of the literature $[7,8]$ and they were collected in Table 1.

The spectra, except for those obtained for as-prepared nanowires and samples annealed at $200^{\circ} \mathrm{C}$, prove the presence of iron oxides, the percentage of which increases with rising annealing temperature. One can conclude that the surfaces of nanowires are being covered by increasing amount of crystalline iron oxides represented by hematite $\left(\alpha-\mathrm{Fe}_{2} \mathrm{O}_{3}\right.$; Fig. 2a) and magnetite $\left(\mathrm{Fe}_{3} \mathrm{O}_{4}\right.$; Fig. 2b). According to [9], the surface oxidation of iron nanostructure in the presence of oxygen-containing atmosphere leads to the formation of iron oxide layer in the form of $\mathrm{Fe}_{3} \mathrm{O}_{4}$ or $\gamma-\mathrm{Fe}_{2} \mathrm{O}_{3}$ (maghemite). However, in the case of large nanostructures, $\mathrm{Fe}_{3} \mathrm{O}_{4}$ is the typically observed form, therefore the Raman signal coming from this iron oxide is predominant for the sample annealed at $300^{\circ} \mathrm{C}$. Moreover, the peaks originating from the $E_{\mathrm{g}}$ vibrational modes of $\alpha-\mathrm{Fe}_{2} \mathrm{O}_{3}$ are also visible at this temperature but their relative intensities are very low. Such observation is possible to detect for large iron nanoobjects, where magnetite changes directly to hematite and maghemite formation is usually omitted [8]. Above $300^{\circ} \mathrm{C}, \mathrm{Fe}_{3} \mathrm{O}_{4}$ converts systematically into the most thermodynamically stable form of iron oxide i.e. $\alpha-\mathrm{Fe}_{2} \mathrm{O}_{3}$. But at the same time iron coming from the core of nanowire is slowly oxidized to the form of $\mathrm{Fe}_{3} \mathrm{O}_{4}$, thus the band with wavenumber of $662 \mathrm{~cm}^{-1}$ is still present for the samples annealed at 400 and $500^{\circ} \mathrm{C}$. The complete transformation of magnetite to hematite can take place at temperatures above $500^{\circ} \mathrm{C}$, so at $800^{\circ} \mathrm{C}$ there is no Raman signal originating from $\mathrm{Fe}_{3} \mathrm{O}_{4}$, what is in good agreement with the reported values of iron oxides phase transitions [8].

More detailed qualitative and quantitative study of iron-containing phases in initial as well as annealed iron nanowires was performed by means of transmission Mössbauer spectroscopy (TMS). Room temperature spectrum collected for as-prepared sample and corresponding distribution of magnetic hyperfine field are presented in Fig. 3a and Fig. 3b, respectively. Three main components of the spectrum are shown: (i) a sharp sextet, being characterized by magnetic hyperfine field $B_{1}=33.0 \div 33.2 \mathrm{~T}$ and isomer shift (in relation to iron as reference) $\delta_{1}=0.0$; (ii) a smeared sextet related to continues distribution of magnetic hyperfine field with average value about $B_{\mathrm{av} .}=23 \mathrm{~T}$ and isomer shift $\delta_{\mathrm{av} .}=0.03 \mathrm{~mm} / \mathrm{s}$; (iii) a smeared component being characterized by high values of magnetic hyperfine field (over $34 \mathrm{~T}$ ). The first component represents crystalline $\alpha$-Fe, while the second one is attributed to an amorphous iron-based phase which possibly contains some contribution of oxygen atoms [10]. The last component, because of high values of magnetic hyperfine field, is attributed to iron oxides which are situated probably at the surface of the nanowires and thereby they are distorted and characterized by many different values of magnetic hyperfine field. The relative contribution of iron atoms belonging to individual phases was evaluated from the area limited by corresponding subspectra. Hyperfine parameters of particular components are presented in Table 2 . The signals coming from the components of intensity below $1 \%$ have been omitted because they are in the same range as a measurement error. Therefore, the summaries of percentage in Table 2 columns do not always reach $100 \%$.

CEMS spectrum collected for as-prepared nanowires is composed of similar components as the transmission spectrum, but intensities of the components are slightly different. In CEMS spectrum (which originates due to interaction of gamma beam with the surface layer of the material) much less contribution of the sharp sextet, representing
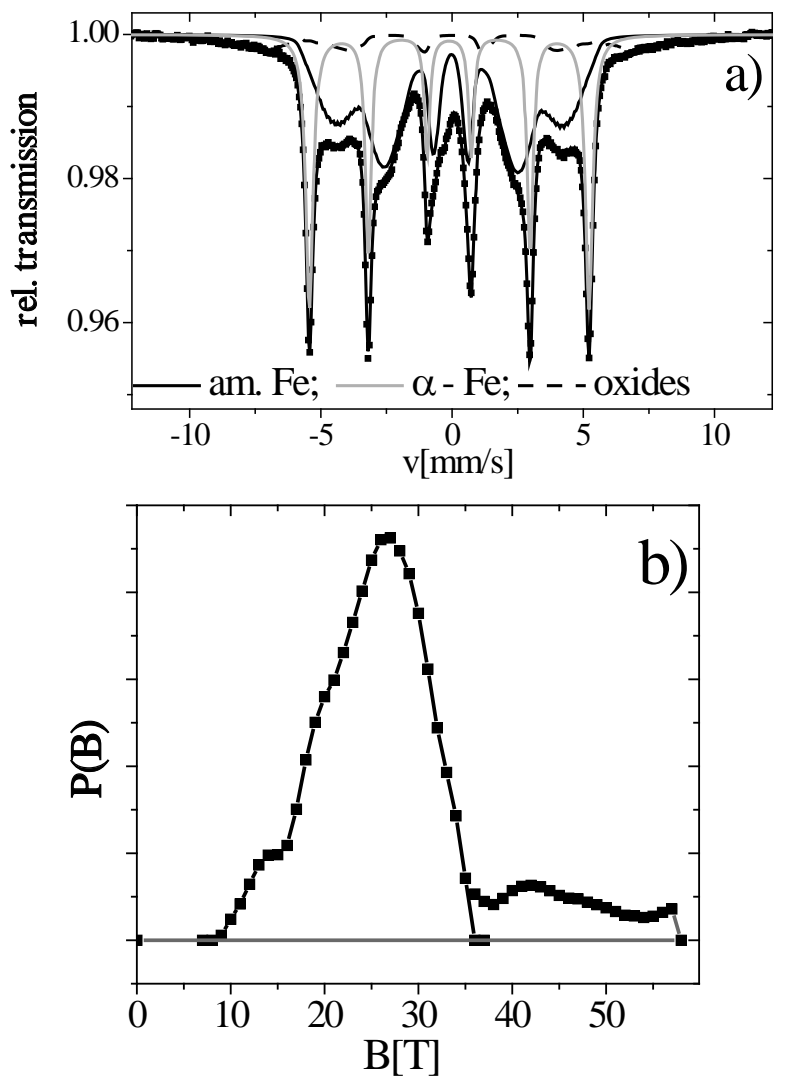

Fig. 3. Mössbauer spectrum collected for as-prepared Fe-nanowires (a) and magnetic hyperfine field distribution derived from the 'continuous' subspectrum (b). 
Table 2. Percentage of the main components of Mössbauer spectra, described in the text (components of intensity below $1 \%$ were omitted)

\begin{tabular}{lccccccc}
\hline & As-prepared & As-prepared & \multicolumn{5}{c}{$T_{\mathrm{a}}\left[{ }^{\circ} \mathrm{C}\right]$} \\
\cline { 5 - 9 } & TMS & CEMS & 200 & 300 & 400 & 500 & 800 \\
\hline Low-field distribution & 54 & 60 & 44 & 31 & 17 & 8 & 2 \\
High-field distribution & 8 & 18 & 6 & 9 & 28 & 18 & - \\
Crystalline $\alpha-F e$ & 33 & 16 & 39 & 25 & 13 & 2 & - \\
Crystalline $\alpha-\mathrm{Fe}_{2} \mathrm{O}_{3}$ & - & 2 & - & 3 & 24 & 61 & 93 \\
Crystalline $\mathrm{Fe}_{3} \mathrm{O}_{4}$ & - & - & - & 2 & 3 & 5 & - \\
Amorphous oxides & 3 & - & 7 & 29 & 13 & 4 & - \\
Surface iron inter. with oxides & - & - & - & - & - & 1 & 5 \\
\hline
\end{tabular}

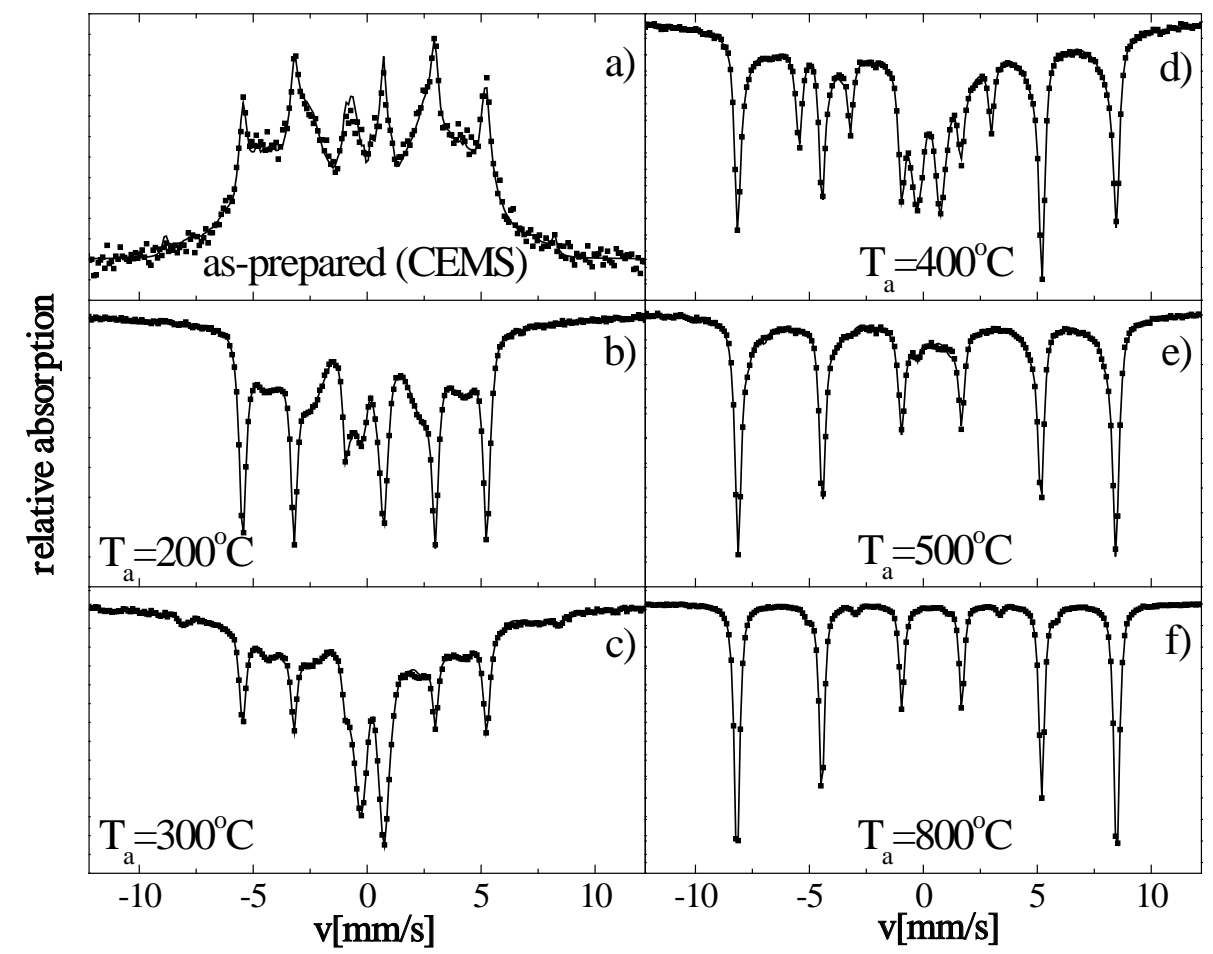

Fig. 4. The Mössbauer spectra, obtained for as-prepared (CEMS spectrum) (a) and annealed (at different temperature $T_{\mathrm{a}}$, under Ar atmosphere) iron nanowires (b-f).

crystalline $\alpha$-iron, is observed. This result proves the hypothesis that crystalline iron constitutes a core of initial nanowires while phases containing oxides are situated mainly at their surfaces.

The components of TMS spectra collected for annealed nanowires evolve depending on the annealing temperature. While the low-field component of the continues distribution decreases monotonically with the increasing $T_{\mathrm{a}}$, the high-field subspectrum at the beginning rises, reaches the maximal value of $28 \%$ for $T_{\mathrm{a}}=400^{\circ} \mathrm{C}$, and then falls to zero for $T_{\mathrm{a}}=800^{\circ} \mathrm{C}$. The intensity of sextet representing $\alpha$-Fe assumes the maximal value of $39 \%$ for $T_{\mathrm{a}}=$ $200^{\circ} \mathrm{C}$ and then decreases gradually to zero. This small increase of crystalline iron content can be explained by the crystallization of a small amount of amorphous iron at low annealing temperatures. In return, three sextets originate, corresponding to crystalline oxides: hematite $-\alpha-\mathrm{Fe}_{2} \mathrm{O}_{3}$ and magnetite - $\mathrm{Fe}_{3} \mathrm{O}_{4}$. Hematite dominates in spectra collected for samples annealed at the highest temperatures: $500^{\circ} \mathrm{C}$ or $800^{\circ} \mathrm{C}$. Additionally, in the spectra a broadened doublet occurs, being characterized by quadrupole splitting $(0.95 \div 1.2) \mathrm{mm} / \mathrm{s}$ and isomer shift $(0.33 \div 0.36) \mathrm{mm} / \mathrm{s}$ (in relation to pure iron). This component can be attributed to amorphous iron oxides (originating mainly from the amorphous iron), which are paramagnetic at room temperature $[11,12]$. We cannot exclude some contribution of superparamagnetic oxides to this component. Relative intensity of the doublet is maximal in spectrum collected for sample annealed at $T_{\mathrm{a}}=300^{\circ} \mathrm{C}$, then it decreases and disappears at $T_{\mathrm{a}}=800^{\circ} \mathrm{C}$. Apart from the dominating sextet which represents hematite, another small sextet (5\%) occurs in Mössbauer spectrum obtained at $T_{\mathrm{a}}=800^{\circ} \mathrm{C}$, with magnetic hyperfine field $33.9 \mathrm{~T}$, isomer shift $0.39 \mathrm{~mm} / \mathrm{s}$ and quadrupole splitting $0.20 \mathrm{~mm} / \mathrm{s}$. A similar component was reported in Mössbauer spectra obtained for iron nanoparticles [13] and can be caused by interaction of surface iron atoms with an oxide shell of particles.

The presented results show that iron oxides, especially hematite, are the final products of annealing of the iron nanowires. Therefore, even though annealing was performed under argon atmosphere, it seems to be much more oxide phases in the final state than in 
the initial one. We suppose that the reason was a large amount of oxygen adsorbed physically at the surface of the as-prepared nanowires, which in this state is not visible for Mössbauer spectroscopy. At high temperature, it reacts with iron forming easily observed oxides. The other possible reason is the insufficiently good quality of argon atmosphere used in the course of annealing. On the other hand, applied flow of inert gas helps to reduce rapid oxidation of iron and also contributes to creation of iron-iron oxide core-shell nanostructures which are thermodynamically stable in the ambient conditions.

\section{Conclusions}

The results of presented investigations proved that as-prepared iron nanowires are consisted of crystalline phase of $\alpha-\mathrm{Fe}$, amorphous iron with possible admixture of oxygen as well as very distorted iron oxides. Contribution of iron oxides increases after thermal treatment to the extent dependent on the annealing temperature. However, at $T_{\mathrm{a}}$ above $400^{\circ} \mathrm{C}$, the most thermodynamically stable oxide form (hematite) dominates. Therefore, well-arranged annealing enables to control easily the type and quantity of iron oxides that prefer to situate on the surface of Fe NWs. This feature can be important from a point of view of future applications.

Acknowledgments. Authors would like to acknowledge Professor M. Szafran and Mrs. A. Szudarska from Warsaw University of Technology for help in annealing processing. This work was supported by the Foundation for Polish Science International PhD Projects Programme co-financed by the EU European Regional Development Fund.

\section{References}

1. Chertok, B., Moffat, B. A., David, A. E., Yu, F., Bergemann, C., Ross, B. D., \& Yang, V. C. (2008). Iron oxide nanoparticles as a drug delivery vehicle for MRI monitored magnetic targeting of brain tumors. Biomaterials, 29(4), 487-496. DOI: 10.1016/j.biomaterials.2007.08.050.

2. Zhang, X. X., Wen, G. H., Huang, S., Dai, L., Gao, R., \& Wang, Z. L. (2001). Magnetic properties of Fe nanoparticles trapped at the tips of the aligned carbon nanotubes. J. Magn. Magn. Mater., 231(1), 9-12. DOI: 10.1016/S0304-8853(01)00134-2.

3. Bolm, C., Legros, J., Le Paih, J., \& Zani, L. (2004). Iron-catalyzed reactions in organic synthesis. Chem. Rev., 104(12), 6217-6254. DOI: 10.1021/cr040664h.

4. Getzlaff, M., Bansmann, J., \& Schonhense, G. (1995). Oxygen on $\mathrm{Fe}(100)$ and $\mathrm{Fe}(110)$. Fresenius J. Anal. Chem., 353(5/8), 743-747. DOI: 10.1007/ BF00321362.

5. Zeeshan, M. A., Pane, S., Youn, S. K., Pellicer, E., Schuerle, S., Sort, J., Fusco, S., Lindo, A. M., Park, H. G., \& Nelson, B. J. (2013). Graphite coating of iron nanowires for nanorobotic applications: Synthesis, characterization and magnetic wireless manipulation. Adv. Funct. Mater., 23(7), 823-831. DOI: 10.1002/ adfm.201202046.

6. Lin, W. S., Jian, Z. J., Lin, H. M., Lai, L. C., Chiou, W. A., Hwu, Y. K., Wu, S. H., Chen, W. C., \& Yao, Y. D. (2013). Synthesis and characterization of iron nanowires. J. Chinese Chem. Soc., 60(1), 85-91. DOI: 10.1002/jccs.201200263.

7. Jubb, A. M., \& Allen, H. C. (2010). Vibrational spectroscopic characterization of hematite, maghemite, and magnetite thin films produced by vapor deposition. ACS Appl. Mater. Interfaces, 2(10), 2804-2812. DOI: $10.1021 /$ am1004943.

8. Cornell, R. M., \& Schwertmann, U. (2003). The iron oxides. Structure, properties, reactions, occurrences and uses. Weinheim, Germany: Wiley-VCH.

9. Wang, C. M., Baer, D. R., Amonette, J. E., Engelhard, M. H., Antony, J., \& Qiang, Y. (2009). Morphology and electronic structure of the oxide shell on the surface of iron nanoparticles. J. Am. Chem. Soc., 131(25), 8824-8832. DOI: 10.1021/ja900353f.

10. Long, G. J., Hautot, D., Pankhurst, Q. A., Vandormael, D., Grandjean, F., Gaspard, J. P., Briois, V., Hyeon, T., \& Suslick, K. S. (1998). Mossbauer-Bauer-effect and x-ray-absorption spectral study of sonochemically prepared amorphous iron. Phys. Rev. B, 57(17), 10716-10722. DOI: 10.1103/PhysRevB.57.10716.

11. Machala, L., Zboril, R., \& Gedanken, A. (2007). Amorphous iron(III) oxide - a review. J. Phys. Chem. B, 111(16), 4003-4018. DOI: 10.1021/jp064992s.

12. Cao, X., Koltypin, Y., Katabi, G., \& Prozorov, R. (1997). Preparation and characterization of amorphous nanometre sized $\mathrm{Fe}_{3} \mathrm{O}_{4}$ powder. J. Mater. Chem., 7(6), 1007-1009. DOI: 10.1039/a606739e.

13. Petrov, Y. I., \& Shafranovsky, E. A. (2012). On the conditions eliciting a detailed structure in the hyperfine field distribution at ${ }^{57} \mathrm{Fe}$ nuclei. Nucl. Instrum. Methods Phys. Res. Sect. B-Beam Interact. Mater. Atoms, 271, 96-101. DOI: 10.1016/j.nimb.2011.10.014. 